\title{
ESTRATEGIA DE COMUNICACIÓN PUBLICITARIA EMOCIONAL PARA EL DESARROLLO DE CAMPAÑAS ATL $Y$ BTL EN EL SECTOR DE LEONIDAS PLAZA, COMERCIAL DULCEMANIA Y ARREGLOS "SARITA" EMOTIONAL PUBLICITY COMMUNICATION STRATEGY FOR THE DEVELOPMENT OF ATL AND BTL CAMPAIGNS IN THE SECTOR OF LEONIDAS PLAZA, COMERCIAL DULCEMANIA AND ARRANGEMENTS "SARITA"
}

\begin{abstract}
Rebeca Estefanía Zambrano Narváez Ingeniera en Marketing.

Universidad Laica Eloy Alfaro de Manabí. Ecuador. E-mail: szszstefanie92@gmail.com ORCID: https://orcid.org/0000-0001- 5815-0747

Jenny Garolina Herrera Bartolomé

Docente de la Uleam. Extensión Bahía de Caráquez, Magister en Marketing.

Universidad Especialidades Espíritu Santo.

Ecuador.

E-mail: jenny.herrera@uleam.edu.ec ORCID: https://orcid.org/0000-0001-5497-9814
\end{abstract}

Recepción: 17/07/2019 Aceptación: 16/09/2019 Publicación: 25/11/2019

\section{Citación sugerida:}

Zambrano Narváez, R. E. y Herrera Bartolomé, J. G. (2019). Estrategia de comunicación publicitaria emocional para el desarrollo de campañas ATL y BTL en el sector de Leonidas Plaza, Comercial Dulcemania y Arreglos "Sarita". 3C Empresa. Investigación y pensamiento crítico, 8(4), 73-93. doi: http://doi. org/10.17993/3cemp.2019.080440.73-93 


\section{RESUMEN}

El presente trabajo de investigación tiene como propósito plantear una propuesta de estrategias de publicidad emocional a través de medios ATL (Above the line, medios tradicionales) y BTL (Below the line, canales más directos) al comercial Sarita. En lo concerniente al problema detectado a través de la entrevistada realizada a la propietaria, no maneja una red social del negocio que permita tener una retroalimentación por parte de los clientes, así como un identificativo externo de la marca. La metodología de la investigación es de carácter bibliográfico, así como los métodos analítico, deductivo, análisis, síntesis, con el fin de obtener información y analizar la investigación realizada a 60 clientes. El Alfa de Cronbach de los datos recopilados fue 0,85 de 1 , dando como resultado fiabilidad en el instrumento aplicado. Referente a la validez se obtuvo un 0,96 de 1 , la misma que se consideró aceptable y con ello correlación con la fiabilidad. Finalmente, se pretende guiar en la comunicación emocional para desarrollar campañas efectivas en los medios ATL y BTL que permitan persuadir al cliente de este negocio y atraer a clientes potenciales.

\section{ABSTRACT}

The present research work has like goal give a propose emotional publicity strategy through de media ATL (Above The Line, traditional media) and BTL (Below The Line, direct channel) to the "Sarita" Commercial. Respect to the scientific problem looked to through to interview to the owner, so they don't use a social network the business that allow received a feedback from the clients, also an out identification of the brand. The research methodology is bibliographic character and, analytic, deductive, and synthetic methods, in order to obtain information and analyze the effected research to 60 costumers. The Alfa the Cronbach to the data looked was 0,85 of 1, giving as a result a friability in the research instrument apply. Referent to the validity was 0,96 of 1, which is acceptable and, with that the correlation and the friability. Finality, it is to guide in the emotional communication in order to develop effect campaign in the media ATL and BTL that allow persuade to costumer of Commercial and, attract potential clients. 


\section{PALABRAS CLAVE}

Comunicación, Campañas, Métodos, Posicionamiento, Emocional.

\section{KEYWORDS}

Communication, Campaign, Methods, Positioning, Emotional. 


\section{INTRODUCCIÓN}

Hoy en día se vive un mundo más globalizado y dinamizado, donde las empresas deben utilizar nuevos elementos que les permita tener un enfoque directo con los clientes y un contacto permanente con los mismos, para de esta manera llegar a un posicionamiento deseado.

De acuerdo con Farrán y López (2010), consideran que la comunicación está ligada a la emocionalidad, pues no solo se trata de ofrecer un discurso publicitario informativo, racional, una propuesta única de valor (USP), que permita persuadir al cliente para que adquiera el bien, hoy esta composición parece no tener correspondencia (p. 44).

A mediados de los 70, David Bernstein catalogó los mensajes publicitarios en dos tipologías según la estructura de su discurso: los mensajes racionales y los mensajes emocionales. A los que cabría unirles una tercera, los mensajes híbridos de ambos: racionales/emocionales. Esta división fue adoptada de inmediato por el mundo profesional y ampliamente estudiada en el ámbito académico. Pero esta división fue el fruto de una profunda observación de la evolución del mensaje publicitario a lo largo de la historia (como se cita en Farrán y López, 2010, p. 45).

Por otro lado, las Estrategias de Comunicación Publicitaria Emocional constituyen hoy una forma eficaz de comunicación que las empresas utilizan para lograr la diferenciación frente a los productos de la competencia despertando la más diversas sensaciones para estimular a sus clientes.

El mundo entero se mueve por emociones. De nada sirven los productos, las marcas o las ideas si no transmiten algo más allá de lo puramente visual o conceptual. Lo que diferencia a unas personas de las otras como consumidores es precisamente el tipo de emociones que las mueven el producto o marca. Sin embargo, muchos anunciantes y agencias siguen olvidándose de generar respuestas emocionales en sus acciones de marketing. Y sin respuestas emocionales, es imposible que una campaña publicitaria genere resultados, branding o recuerdo (Sergi, 2011). 
Los anuncios que apelan a las emociones consiguen, según un análisis desde el punto de vista neurológico, quedarse en la memoria a largo plazo (es decir, la que importa, la que crea los recuerdos). Además, conectan con el punto de decisión de compra. Cada vez que un consumidor adquiere un producto, lo hace de una forma subjetiva. No se trata de una decisión tomada por nuestro cerebro racional o consciente, por lo que llegar con el mensaje a la parte emocional del cerebro es especialmente importante (Pico, 2014).

Por lo general, la publicidad Above The Line (ATL) es una forma más masiva de promocionar la marca, donde la publicidad podrá ser recibida por el público objetivo y también por personas que no pertenezcan a este segmento. Below The Line (BTL) emplea canales más directos, es más cercano e impacta públicos más pequeños, logrando, por lo general, mayor recordación y sorpresa. Es probable que el BTL solo sea dirigido al target de la marca (Hernández, 2015).

Si bien los medios ATL (radio, TV, cine, exteriores) son medibles, resultan estáticos y requieren de un consumidor cautivo, ya sea frente a una pantalla o con una radio encendida, mientras que los medios BTL tienen la virtud de la movilidad, de acompañar al consumidor en sus actividades diarias. Regalar volantes en un semáforo es un clásico ejemplo de una actividad BTL, siempre y cuando el lugar y el consumidor sean congruentes con el producto que forma parte del volanteo. En caso opuesto estaríamos hablando de otro medio más de ATL. Pero en cambio, si estamos frente a un anaquel de cereales y una promotora nos ofrece una degustación de una nueva marca de dicha categoría, el impacto puede ser inmediato y certero. Estos medios cumplen funciones muy diferentes a los BTL. Por lo general, son estratégicos, contribuyen a la construcción de una marca y de su posicionamiento en la mente de sus consumidores. En cambio, los medios BTL, además de contribuir a lo primero, apelan a necesidades tácticas y de corto plazo. Funcionan muy bien para reducir inventarios de lento movimiento, para recuperar las ventas de alguna región, o para disminuir el impacto de algún competidor (Geifman, 2015).

El propósito de esta investigación es plantear una propuesta de estrategias de Publicidad ATL y BTL al Comercial Dulcemania y Arreglos "Sarita”, ya que es un local nuevo en el sector de Leónidas Plaza, con 
esto, se pretende guiar en la comunicación emocional para desarrollar campañas efectivas en los medios ATL y BTL que permitan persuadir al cliente de este negocio y atraer a clientes potenciales.

\section{MARCO TEÓRICO}

\subsection{COMUNICACIÓN PUBLICITARIA EMOCIONAL}

López (2007) alega que: "la publicidad emocional entendida como la persuasión dirigida a los sentimientos del público, se centra ante todo en cubrir sus deseos y anhelos profundos de manera real o simbólica”.

Solorio (2013) considera que:

Una estrategia de comunicación es importante tener claro que es lo que quieres comunicar a los clientes, partiendo de esto se debe planear una mezcla promocional de publicidad y relaciones públicas. Las estrategias de comunicación se basan en la distribución de los anuncios a lo largo de la duración de la misma, es decir, dependiendo del plan promocional y los objetivos con los que se cuente se definirán la estrategia a utilizar.

\subsection{ESTRATEGIA EMOCIONAL}

La estrategia emocional se fundamenta con datos obtenidos del entorno, por ello, al definir una estrategia emocional, se debe considerar los acontecimientos que se presentan a diario en el medio y se deben encausar, recrear y adaptar a pruebas piloto para posteriormente fortalecer la estrategia inicial (Cisneros, 2013).

Ceruelo y Gutiérrez (2003) expresan que cuando lo que se busca es que las emociones actúen como un recurso, las campañas publicitarias se esbozan para no pasar inadvertidas. Para ello se considera el humor, a la exageración e, incluso, al doble sentido. Este tipo de menciones proporciona generalmente poca información sobre las cualidades de los productos exhibidos; más bien, las emociones actúan como 
un señuelo para captar la atención del target. La validez de esas campañas se revela en un aumento de la notoriedad del anuncio y, por ende, de la marca expuesta. A su vez, es posible que la evaluación positiva de los anuncios por parte del espectador permita una actitud positiva hacia la marca.

\subsection{MEDIOS PUBLICITARIOS DE LA COMUNICACIÓN}

Kotler y Armstrong (2012) consideran a los medios publicitarios como "vehículos que se utilizan para entregar los mensajes publicitarios a su público previsto" (p. 444).

En este sentido, son el transporte que los negocios emplean por medio de mensajes estructurados para dar a conocer los productos o servicios que ofertan y que al final capten la atención de su segmento.

\subsubsection{PERFILES DE LOS PRINCIPALES MEDIOS}

El auge de soportes emergentes y los medios tradicionales prestan a las marcas importantes oportunidades para acercarse al consumidor de forma cada vez más personalizada (Kotler y Armstrong, 2012, p. 447).

Cada medio es fundamental en una campaña publicitaria. Por ello, es importante no centrarse en un solo medio sino combinar varios medios de comunicación e integrarlas.

Por consiguiente, se debe tener en cuenta aspectos como características del medio (duración, tamaño, forma), costos, atributos y audiencia para decidirse por el o los medios idóneos para el negocio (Soria, 2015, p. 63).

Tabla 1. Ventajas y desventajas de los principales medios.

\begin{tabular}{|c|c|c|}
\hline Medios & Ventajas & Desventajas \\
\hline Televisión & $\begin{array}{c}\text { Gran eficacia por el impacto visual y auditivo. Variedad de } \\
\text { formatos permite segmentar a los públicos sobre los que } \\
\text { se dirige la publicidad, y el horario en el que puede resultar } \\
\text { más eficaz el mensaje }\end{array}$ & $\begin{array}{c}\text { Publicidad más costosa debido a la inversión en producción } \\
\text { y externalización de servicios a una agencia de publicidad. }\end{array}$ \\
\hline
\end{tabular}




\begin{tabular}{|c|c|c|}
\hline Medios & Ventajas & Desventajas \\
\hline Periódicos & $\begin{array}{l}\text { Presenta amplia cobertura, ya que posee distribución } \\
\text { provincial, regional o nacional. } \\
\text { Diferentes precios según día, tamaño y sección. }\end{array}$ & $\begin{array}{c}\text { La mayor parte de los periódicos ha sufrido una caída } \\
\text { importante en número de lectores debido a la irrupción de la } \\
\text { prensa en Internet. }\end{array}$ \\
\hline Internet & $\begin{array}{l}\text { Medio de comunicación gratuito al que tiene acceso } \\
\text { cualquier target. } \\
\text { Son más económicos y tienen amplia cobertura desde } \\
\text { cualquier parte del mundo se puede acceder. }\end{array}$ & $\begin{array}{l}\text { Es difícil controlar el tipo de usuario al que le llega el } \\
\text { mensaje publicitario (mayor exposición a público joven). La } \\
\text { eficacia publicitaria no es igual en todos los formatos en los } \\
\text { que se presenta en Internet }\end{array}$ \\
\hline $\begin{array}{l}\text { Correo } \\
\text { directo }\end{array}$ & $\begin{array}{l}\text { Alta selectividad de público; flexibilidad; no hay } \\
\text { competencia publicitaria dentro del mismo medio; permite } \\
\text { la personalización. }\end{array}$ & $\begin{array}{l}\text { Costo relativamente alto por exposición; imagen de "correo } \\
\text { no deseado". }\end{array}$ \\
\hline Revistas & $\begin{array}{l}\text { Los lectores son exigentes y leen con atención todos los } \\
\text { contenidos. }\end{array}$ & $\begin{array}{l}\text { La inserción publicitaria es costosa debido a que la tirada, a } \\
\text { diferencia de los periódicos, es menor. }\end{array}$ \\
\hline Radio & $\begin{array}{l}\text { Llega a un público muy heterogéneo, puesto que es un } \\
\text { medio seguido por la mayor parte de la ciudadanía. Coste } \\
\text { bajo-medio }\end{array}$ & $\begin{array}{l}\text { En ocasiones es difícil que el oyente mantenga la atención, } \\
\text { puesto que es un medio que carece de imagen. }\end{array}$ \\
\hline Exteriores & $\begin{array}{l}\text { Flexibilidad; alta exposición repetida; bajo costo; poca } \\
\text { competencia de mensajes; buena selectividad de } \\
\text { ubicación. }\end{array}$ & Poca selectividad de públicos; limitaciones creativas. \\
\hline
\end{tabular}

Fuente: (Soria, 2015, pp. 64-68; Kotler y Armstrong, 2012, p. 447).

De acuerdo con un estudio realizado por la empresa Informedia, empresa especializada en auditoría y estadísticas publicitarias, mencionan que los medios tradicionales ecuatorianos durante el año 2014, la inversión decreció 13,9\% en octubre del año pasado con respecto al mismo mes de 2014. Y, en términos generales, hubo una disminución del acumulado (enero a octubre de 2015) de 10,4\% con respecto a 2014.

Referente a la inversión publicitaria en la televisión se considera el 58\% del mercado publicitario en paralelo con la prensa que le sigue con el 15\%, es decir, existe una diferencia de 43\%. En tercer lugar, está la radio con el 14\%, apenas un punto porcentual por debajo de la prensa y la vía pública (vallas publicitarias, paradas de bus, centros comerciales, etc.) con el 7\%. Finalmente, la revista y los suplementos se encuentran en el último lugar con apenas el 3\% cada uno (El telégrafo, enero 05, 2016). 
Un estudio realizado en Ecuador por la empresa Publimark durante el año 2018, revela la distribución de la audiencia en cada una de las redes sociales. Facebook lidera con 12.00 millones usuarios, distribuidos en $48 \%$ mujeres y $52 \%$ hombres. Instagram en segundo lugar con 3.90 millones de usuarios, divididos en $55 \%$ mujeres y $45 \%$ hombres. Esta red cuenta con un crecimiento de 2,6\% trimestral. En tercer lugar, se encuentra Twitter con 790 mil usuarios, de los cuales el 30\% son mujeres y el 70\% son hombres. Con un decrecimiento semestral de 6,3\%. Finalmente, en el caso de LinkedIn, cuenta con 2.20 millones de usuarios, repartidos en un $46 \%$ mujeres y el $54 \%$ hombres. Su crecimiento trimestral es de 4,8\% (Briceño, 2019). El crecimiento de la publicidad digital según datos proporcionados por Interactive Advertising Bureau (IAB) en el año 2013 se presenta un 50\% en la inversión de publicidad por internet en el país. Se enfatiza que hubo un aumento tanto en display con el 55\%, redes sociales con el 33\% y móvil en el 12\% (El Universo, 2014).

Tomando en cuenta estos datos estadísticos de Ecuador, en los medios tradicionales aún tienen su respectiva audiencia, aunque poco a poco va decreciendo la inversión publicitaria. Referente a los medios digitales, han cambiado la forma de publicitar los negocios y marcas, pues, las personas cada vez más utilizan las redes sociales para informarse al instante de lo que sucede en su ciudad o a nivel mundial. En este sentido, los negocios ven una oportunidad para promocionar sus productos o servicios sin ser intrusivos y dirigiéndose a su público objetivo, ya que las redes permiten segmentar su audiencia y llevar estadísticas en tiempo real de lo que se publica. Sin embargo, es importante que las empresas estudien su nicho y con ello elegir medios acordes no solo ATL sino también BTL, y, posterior a ello, diseñar mensajes idóneos y creativos para su mercado.

\section{METODOLOGÍA}

La metodología de la investigación es de carácter bibliográfico y de campo por medio de la observación, debido a que se realizan búsquedas de conceptos definiciones e ideas, entre las fuentes de información se encuentran: libros, tesis de páginas web, revistas científicas, artículos científicos entre otros. 
Los métodos aplicados en esta investigación son: método analítico, deductivo, análisis, síntesis, teóricos con el fin de obtener información y analizar la investigación.

En el presente trabajo se utilizará como instrumento la encuesta y la entrevista, la cual permitirá reunir información necesaria para el desarrollo del mismo.

Gracia, Socorro y Martin (2014) afirman que "las muestras no probabilísticas no representan con exactitud a la población. Sin embargo, resultan satisfactorias, y hasta deseables, para ciertos propósitos de investigación. Con mayor frecuencia obedecen a la imposibilidad de que los investigadores obtengan muestras representativas".

La muestra no probabilística por conveniencia que se aplicará en la presente investigación es de 60 clientes del Comercial Dulcemania y Arreglos "Sarita", pues el negocio no cuenta con una base de datos que permita aplicar otro tipo de muestreo.

En relación con el tema que se está tratando se puede decir que el método aplicado, como se visualiza en la Tabla 2, demuestra que la fiabilidad está en un 0,85 de 1, dando como resultado del Alfa de Cronbach de los datos recopilados.

Tabla 2. Estadísticas de fiabilidad.

\begin{tabular}{|c|c|}
\hline Alfa de Cronbach & N de elementos \\
\hline, 846 & 6 \\
\hline
\end{tabular}

Fuente: elaboración propia.

Referente a la validez del instrumento, de acuerdo con la Tabla 3, se obtuvo un 0,96 de 1, la misma que es aceptable y tiene correlación con la fiabilidad. 
Tabla 3. Resumen del modelob.

\begin{tabular}{|c|c|c|c|c|c|c|c|c|c|c|}
\hline \multirow[b]{2}{*}{ Modelo } & \multirow[b]{2}{*}{$\mathbf{R}$} & \multirow[b]{2}{*}{$\begin{array}{c}\mathbf{R} \\
\text { cuadrado }\end{array}$} & \multirow[b]{2}{*}{$\begin{array}{l}\text { R cuadrado } \\
\text { ajustado }\end{array}$} & \multirow[b]{2}{*}{$\begin{array}{c}\text { Error } \\
\text { estándar de } \\
\text { la estimación }\end{array}$} & \multicolumn{5}{|c|}{ Estadísticos de cambio } & \multirow[b]{2}{*}{$\begin{array}{l}\text { Durbin- } \\
\text { Watson }\end{array}$} \\
\hline & & & & & $\begin{array}{l}\text { Cambio en } \\
R \text { cuadrado }\end{array}$ & $\begin{array}{c}\text { Cambio } \\
\text { en F }\end{array}$ & gl1 & gl2 & $\begin{array}{c}\text { Sig. } \\
\text { Cambio } \\
\text { en F }\end{array}$ & \\
\hline 1 & ,859a & ,738 & ,714 & ,20862 & ,738 & 30,482 & 5 & 54 &, 000 & 1,749 \\
\hline
\end{tabular}

Fuente: elaboración propia.

\section{RESULTADOS}

De acuerdo con la investigación realizada en el sector de Leónidas Plaza, se explica sobre las preguntas de control de la encuesta realizada en el local Dulce Manía y Arreglos "Sarita":

De acuerdo con la Tabla 4, el 48,3\% de los encuestados consideran que se debe crear una cuenta en Instagram para poder realizar el seguimiento de la misma y así visualizar el contenido, mientras que el $36,7 \%$ dijeron que es conveniente crear una cuenta en Facebook.

Como resultado, se afirma que se debe crear una cuenta en Instagram, para que sus clientes realicen el seguimiento y publicitar más sobre los productos y servicios que el comercial brinda.

Tabla 4. ¿En cuál de estos medios digitales usted considera q debe realizar publicidad el Comercial Dulcemania y Arreglos "Sarita"?

\begin{tabular}{|c|c|c|c|c|c|}
\cline { 3 - 6 } & Frecuencia & Porcentaje & Porcentaje válido & Porcentaje acumulado \\
\hline \multirow{2}{*}{ Válido } & Twitter & 1 & 1,7 & 1,7 & 1,7 \\
\hline \multirow{2}{*}{ Facebook } & 22 & 36,7 & 36,7 & 38,3 \\
\cline { 2 - 6 } & Instagram & 29 & 48,3 & 48,3 & 86,7 \\
\cline { 2 - 6 } & WhatsApp & 7 & 11,7 & 11,7 & 100,0 \\
\cline { 2 - 6 } & YouTube & 1 & 1,7 & 1,7 & \\
\hline
\end{tabular}

Fuente: encuesta realizada en el comercial "Sarita". 
Como se observa en la Tabla 5, el 65\% piensan que se debe realizar vallas publicitarias para el reconocimiento del Comercial, mientras que el 16,7\% de los encuestados eligieron hojas volantes para el conocimiento de los productos y servicio que el Comercial ofrece.

Con respecto a los resultados se realizarán vallas publicitarias para así dar a conocer su lugar de atención y también sobre las promociones que realiza el Comercial.

Tabla 5. ¿En cuál de estos medios tradicionales usted considera que debe realizar publicidad el Comercial Dulcemania y Arreglos "Sarita"?

\begin{tabular}{|c|c|c|c|c|c|}
\cline { 2 - 5 } & & Frecuencia & Porcentaje & Porcentaje válido & Porcentaje acumulado \\
\hline \multirow{2}{*}{ Válido } & Reriódicos & 1 & 15,0 & 15,0 & 15,0 \\
\cline { 2 - 6 } & Hojas volantes & 10 & 1,7 & 1,7 & 16,7 \\
\cline { 2 - 6 } & Publicidad móvil & 1 & 16,7 & 16,7 & 33,3 \\
\cline { 2 - 6 } & Vallas publicitarias & 39 & 65,0 & 1,7 & 35,0 \\
\hline
\end{tabular}

Fuente: encuesta realizada en el comercial "Sarita".

En lo que corresponde a la Tabla 6, el 81,7\% afirmaron que si existiese una campaña publicitaria esta incentivaría a sus clientes a visitar el negocio, mientras que el 18,3\% respondieron que están de acuerdo con la misma.

En lo correspondiente a la publicidad, la mayoría de los clientes afirman que desearían que se aplique una campaña publicitaria para incentivar a visitar el Comercial.

Tabla 6. ¿Cree usted que se generaría un mayor número de ventas, si existiera una campaña publicitaria que incentive a los clientes a visitar el Comercial Dulcemania y Arreglos "Sarita"?

\begin{tabular}{|c|c|c|c|c|c|}
\cline { 2 - 6 } & & Frecuencia & Porcentaje & Porcentaje válido & $\begin{array}{c}\text { Porcentaje } \\
\text { acumulado }\end{array}$ \\
\hline \multirow{2}{*}{ Válido } & De acuerdo & 11 & 18,3 & 18,3 & 18,3 \\
\cline { 2 - 6 } & Totalmente de acuerdo & 49 & 81,7 & 81,7 & 100,0 \\
\hline
\end{tabular}

Fuente: encuesta realizada en el comercial "Sarita". 
Entrevista a la dueña del Comercial Dulcemania y Arreglos "Sarita", cuyo objetivo es conocer la publicidad que aplica dentro del mismo.

1. ¿Actualmente usted realiza alguna publicidad para el reconocimiento de los productos y servicios que presta su negocio?

En radio, en mi cuenta de Facebook y WhatsApp personal.

2. ¿Cree usted que los medios de publicidad utilizados actualmente en su negocio son los más adecuados? Si, ya que si ha sabido llegar a sus clientes.

3. ¿Qué medios usted considera eficaz para lograr el reconocimiento de su negocio?

$\begin{array}{ll}\text { Twitter }(\text { ) } & \text { Radio }(\mathrm{X}) \\ \text { Facebook }(\mathrm{X}) & \text { Periódicos ( ) } \\ \text { Instagram (X) } & \text { Hojas volantes ( ) } \\ \text { WhatsApp (X) } & \text { Publicidad móvil ( ) } \\ \text { YouTube ( ) } & \text { Vallas publicitarias (X) }\end{array}$

4. ¿Cuán importante es para usted la publicidad emocional dentro de su negocio?

Es muy importante ya que se incentiva al cliente a comprar y acceder a mis productos y servicios.

5. ¿Considera usted que al crear una publicidad con contenido emocional aportaría valor y mejoramiento a sus ventas?

Claro que sí, ya que en este siglo veintiuno la gente visualiza bastante la publicidad y eso hace que los clientes accedan a mi Comercial y generen más ventas. 
Cabe señalar que tanto los clientes encuestados como la propietaria del comercial entrevistado consideran que se deben estructurar y desarrollar en conjunto publicidad emocional tanto en medio tradicional (valla publicitaria) y digital (red instagram) para generar un excelente posicionamiento de la marca.

\section{DESARROLLO DE LA PROPUESTA}

Instagram es una plataforma muy atractiva para la mayoría de los jóvenes, y las marcas están apostando por usarla cada vez más en su estrategia de marketing. Se ha convertido en una red social que abarca contenidos visuales, que cada vez atrae más al público joven y empresas que desean atraer a su target. Así también cuenta con ventajas que están siendo aprovechadas por sus usuarios. Además, estas ventajas de Instagram ayudan en la estrategia de Marketing Digital para las marcas (Salinas, 2017).

De acuerdo con la investigación realizada para este negocio, se determinó que los clientes prefieren Instagram para conocer mejor sobre los productos y servicios que se expenden. Por ello, es importante fundamentar las ventajas del mismo como herramienta de marketing para tener mayor eficacia al momento de manejar este tipo de red social.

Entre las ventajas es que permite crear marcas, pues las personas les agradan visualizar imágenes y se sienten atraídas. Otra ventaja es que permite sincronizar con otras redes sociales como Facebook y Twitter, de esta forma llegar con el contenido a otros perfiles. Se puede interactuar con los seguidores, de esta forma se obtiene un feedback del público objetivo, a su vez, el uso del hashtag para que compartan sus experiencias con este símbolo y el nombre de la marca. La gran mayoría de personas emplean el celular, y esta red cuenta con la aplicación que se adapta al teléfono y con ello permite visualizar las publicaciones realizadas.

Instagram $A d s$ proporciona herramientas en donde se puedan diseñar anuncios visuales que consienten humanizar la marca y conseguir nuevas audiencias. Otro punto clave es la geo-localización que se puede agregar en las fotos la ubicación, con ello, el negocio puede obtener mayor visibilidad. 
Entre alguno de los objetivos de esta rede se encuentran: Crear imagen de marca, exponer las novedades del negocio, publicar sobre los productos y servicios, incrementar las ventas, mayor engagement, fortalecer los productos más relevantes del comercial (Digitalmenta, 2018).

Basándose en lo antes manifestado, se diseña la red social Instagram, con el fin de ejemplificar y dar a conocer que se puede desarrollar estrategias emocionales para generar fidelización en los seguidores de la cuenta Dulce Manía y arreglos "Sarita".

Como se observa en la Figura 1, aplica todas las funciones aprovechables para la cuenta de negocio. En su perfil, expresan su dirección, la categoría a la que pertenece (Comercial). Las imágenes publicadas evidencian su trabajo, esto genera interacción del usuario, además de dar a conocer los productos y servicios que oferta el negocio.

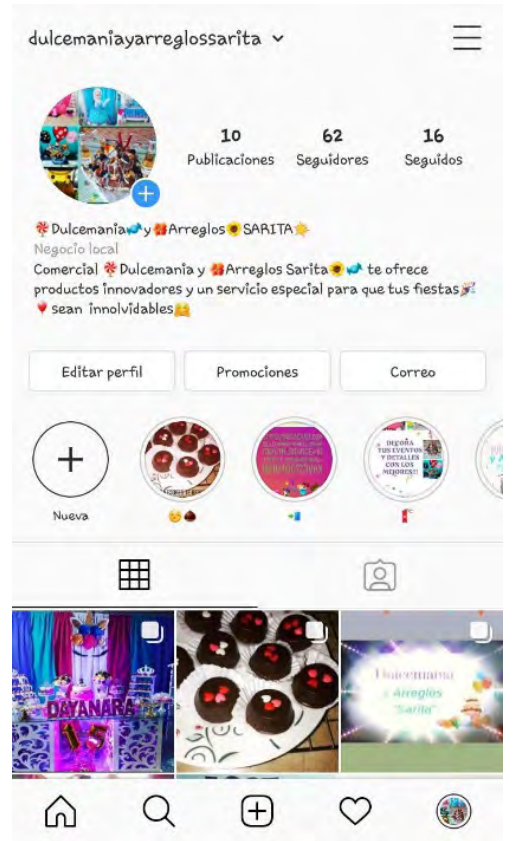

Figura 1. Diseño de la cuenta Instagram Comercial "Sarita”. Fuente: Instagram dulcemaniayarreglossarita. 

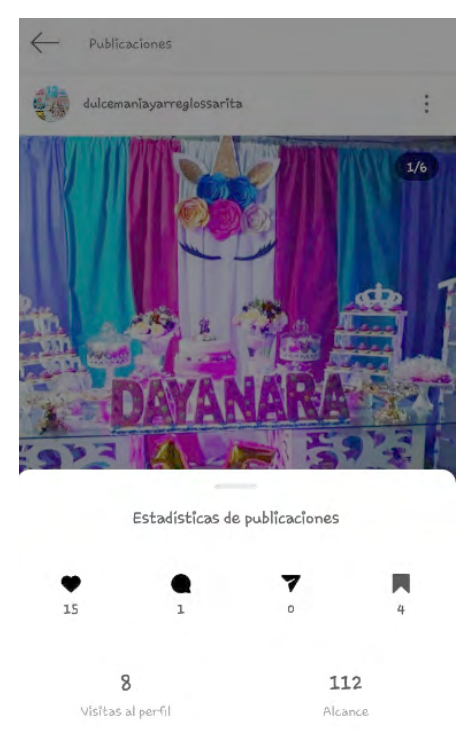

Figura 2. Estadística de publicación comercial "Sarita". Fuente: Instagram dulcemaniayarreglossarita.

En la Figura 2 se visualiza los resultados de una publicación, para conocer el desempeño, obteniendo un alcance de 112 de usuarios que han visto la publicación durante los tres primeros días de compartir la publicación. Es decir, que para ser una cuenta recién creada y con 62 seguidores, lo que significa que lo han visualizado más de una vez.

Por otra parte, de acuerdo con la encuesta realizada, el 65\% de los clientes consideran que se debe publicitar por medio de vallas. Por consiguiente, Martínez (2018) argumenta que las vallas son uno de los recursos más simbólicos y efectivos para influir en el cliente, sobre todo para realizar acciones promocionales, y su aplicación estima un gran valor añadido a las campañas de comunicación lanzadas por las marcas, ya que fortifica ampliamente los estímulos enviados por estas a través de otra clase de medios, bien sean anuncios en TV, en periódicos, en revistas, en redes sociales, entre otros canales (p. 154). 
$\mathrm{Al}$ respecto conviene decir que las vallas son una herramienta visual para promocionar y publicitar una marca y por medio del uso de elementos visuales grandes ubicados en puntos estratégicos en vías y calles de la ciudad donde hay gran flujo de gente. Su objetivo es llamar la atención de posibles consumidores y lograr que las personas que son expuestas al mensaje recuerden la marca. Por ello, debido al tiempo de exposición limitado que tienen las vallas publicitarias, el mensaje de marca debe ser corto y fácil de entender, de lo contrario el consumidor no entenderá el mensaje y la marca no será recordada. Por lo normal una valla tiene aproximadamente 3 segundos de exposición (Vasconez, 2016).

Existen diversos tipos de vallas publicitarias, por lo que resulta un formato muy versátil y, en función de sus particularidades, captan de una u otra manera la atención del público objetivo. Las más utilizadas son las vallas clásicas o tableros de anuncios, valla publicitaria de vinil, posters, vallas en 3D, vallas y pantallas digitales, vallas palomeras, vallas de tres caras, las iluminadas y las rotatorias. Además de las vallas, existen otros soportes exteriores muy utilizados por los negocios del sector, como son los mupis, las lonas o las marquesinas de los autobuses (Grupo Graphic, 2014).

De esta circunstancia nace el hecho de que se diseñe una valla publicitaria tipo palomera que permita identificar externamente al negocio a su vez mejorar su imagen y su reconocimiento en el sector, dentro de este contenido se visualizará la ubicación del Comercial, imágenes de calidad referente a los productos y servicios, dirección de la red social, estos detalles permitirán generar interés emocional a la hora de adquirir los productos de esta índole. 

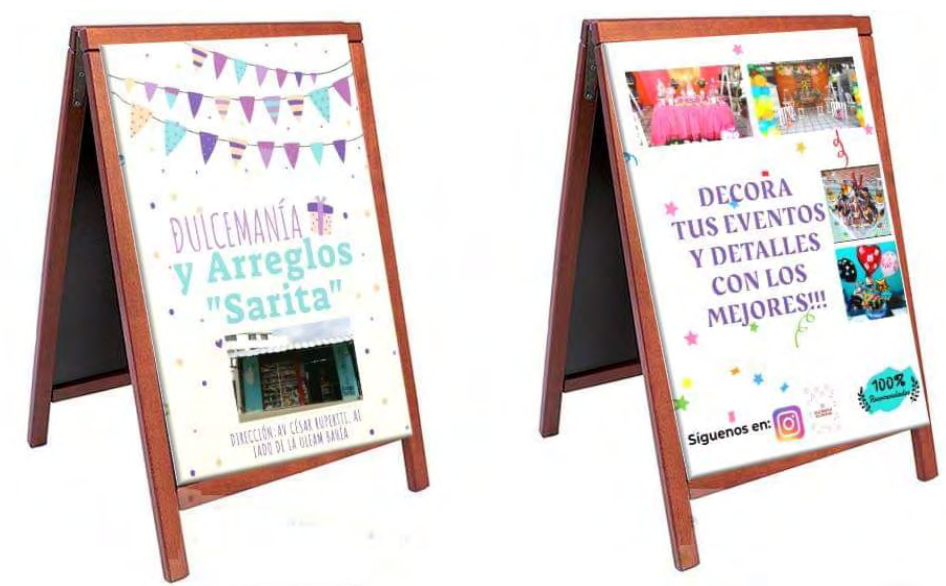

Figura 2. Parte trasera y frontal de Tipo paloma publicitaria. Fuente: elaboración propia.

La exposición constante de la valla tipo palomera en las afueras del local permitirá cautivar a los clientes actuales y potenciales de una forma más eficiente al entregar un mensaje oportuno con diseño creativo y alternativo, empleando imágenes en alta resolución, con un material adecuado y resistente a las condiciones, características de los espacios exteriores. Diseñado con contenido simple, conciso y convincente, pues, se debe captar la atención del transeúnte entre los 5 a 7 segundos de exposición.

\section{CONCLUSIONES}

Tomando como base la literatura investigada, se concluye que la publicidad en medios ATL y BTL tiene mayor impacto si se aplican estrategias de comunicación emocional, pues estas actúan como un estímulo para captar la atención del target por medio de mensajes basados en la empatía y el conocimiento del otro.

En la investigación realizada a las 60 personas seleccionadas en la muestra no probabilística por conveniencia, se pudo conocer los medios de comunicación tradicional y digital que los usuarios prefieren recibir información del Comercial "Sarita". Por tanto, se fundamenta la propuesta para promocionar 
a través de la red social Instagram y la valla publicitaria los productos y servicios que oferta y de esta manera generar un mejor engagement, y a su vez, quien administra el negocio sea consciente de los gustos comunicacionales de su público objetivo.

Según los datos estadísticos obtenidos, los medios tradicionales han decaído en un 13,4\% en el país, no obstante, ello no significa que no se deban aplicar, ya que estos se mantienen según la necesidad de cada ciudad, como lo evidencia la encuesta, donde los clientes consideran con un $65 \%$ el uso de valla publicitaria. Por otro lado, el auge del internet dio paso a la publicidad digital y en especial a través de las redes sociales con un 50\%. A pesar de que Facebook es la red social preferida, sin embargo, los entrevistados eligieron Instagram con un 48,3\%, con ello, y de acuerdo con las estadísticas denota el crecimiento y aceptación de esta aplicación para estructurar campañas efectivas, pues, los usuarios pueden interactuar y así también el negocio puede obtener un feedback real, para potenciar sus estrategias publicitarias.

Finalmente, es primordial que al estructurar mensajes con contenido emocional permita quedarse en la memoria a largo plazo (es decir, la que trasciende, la que genera los recuerdos). Así también, enlazan con el punto de disposición de compra, por lo que llegar con el anuncio a la parte emocional del cerebro es esencialmente importante.

\section{REFERENCIAS BIBLIOGRÁFICAS}

Briceño, D. (2019). Publimark. Recuperado el 7 de septiembre de 2019, de https://publimark. ec/2019/04/11/datos-importantes-sobre-el-comportamiento-digital-en-ecuador-2019/

Geruelo, G., y Gutiérrez, A. M. (2003). Eficacia de la Publicidad Emocional. Un Estudio Comparativo entre la Ejecución de Tipo Emocional e Informativa. Universidad de Valladolid. Documento de Trabajo 09/03. Recuperado el 3 de septiembre de 2019, de https://gredos.usal.es/bitstream/ handle/10366/75262/DAEE_09_03_Eficacia.pdf?sequence=1\&isAllowed=y 
Gisneros, E. A. (2013). Neuromarketing y neuroeconomía: código emocional del consumidor (2a ed.). Bogotá: Ecoe. Recuperado el 3 de septiembre de 2019, de https://ebookcentral.proquest.com/lib/uleamecsp/ reader.action?docID $=4870560 \&$ query $=$ estrategia $\% 2$ Bcomunicacion $\% 2$ Bemocional

Digitalmenta. (29 de agosto de 2018). Recuperado el 8 de septiembre de 2019, de https://www. digitalmenta.com/social-ads/estrategia-marketing-instagram/

El telegrafo. (5 de enero de 2016). Recuperado el 7 de septiembre de 2019, de https:/ /www.eltelegrafo. com.ec/noticias/medios / 1 /la-publicidad-cae-el-13-9-en-los-medios-tradicionales-peroaumenta-en-sitios-web

E1 Universo. (11 de abril de 2014). Recuperado el 7 de septiembre de 2019, de https:/ / www.eluniverso. com/noticias/2014/04/11/nota/2675316/publicidad-digital-pais-crecio-50

Farrán, E., y López, R. (2010). La evolución del discurso racional al discurso emocional en El Sol. Comunicación y Hombre, (6), 43-63. Recuperado el 3 de Agosto de 2019, de https://www.redalyc. $\mathrm{org} / \mathrm{pdf} / 1294 / 129418690003 . p d f$

Geifman, A. (23 de enero de 2015). Forbes. Recuperado el 6 de enero de 2019, de https://www.forbes. com.mx/que-es-el-btl-y-por-que-sigue-siendo-importante/

Gracia, G. C., Socorro, O. O., y Martin, G. (2014). Metodologia de la Investigacion (1 ${ }^{\mathrm{a}}$ ed.). Mexico: Grupo Editorial Panta. Recuperado el 25 de enero de 2019, de https://ebookcentral.proquest.com/lib/ uleamecsp $/$ reader.action? docID $=3227245 \&$ query $=$ metodologia + de + la + investigaci $\% \mathrm{C} 3 \% \mathrm{~B} 3 \mathrm{n}$

Grupo Graphic. (7 de marzo de 2014). Recuperado el 8 de septiembre de 2019, de https:/ / grupographic. com/tipos-de-vallas-publicitarias/

Hernández, A. (24 de Septiembre de 2015). Marketing to Marketing. Recuperado el 7 de enero de 2019, de https://m2m.com.co/actualidad/para-ganar-la-guerra/

Kotler, P., y Armstrong, G. (2012). Marketing. México: Pearson Educación. Recuperado el 7 de septiembre de 2019 
López, B. (2007). Publicidad Emocional Estrategias Creativas. Madrid: ESIC. Recuperado el 25 de abril de 2019

Martínez, G. (2018). Marketing y comunicación de moda. Madrid: ESIC. Recuperado el 8 de septiembre de 2019, de https://ebookcentral.proquest.com/lib/uleamecsp/reader. action? docID $=5758476 \&$ query $=$ vallas $\% 2$ Bpublicitarias

Orozco,J. A. (2007). Diseño y Construccion de marca a traves de medios ATLy BTL. Recuperado el 25 de abril de 2019, de https://fido.palermo.edu/servicios_dyc/encuentro2007/02_auspicios_publicaciones/ actas_diseno/articulos_pdf/A6046.pdf

Pico, R. G. (11 de junio de 2014). Puro marketing. Recuperado el cinco de Enero de 2019, de https:// www.puromarketing.com/9/22380/como-publicidad-emocional-puede-transmitir-mensajesimportan.html

Salinas, A. (11 de agosto de 2017). Mott.pe. Recuperado el 27 de enero de 2019, de https://mott. marketing/informacion-sobre-la-historia-servicios-caracteristicas-de-la-red-social-instagram/

Sergi, M. (5 de diciembre de 2011). Puro Marketing. Recuperado el cinco de enero de 2019, de https:// www.puromarketing.com/44/11529/poder-publicidad-emocional-marcas.html

Solorio, W. M. (31 de diciembre de 2013). Estrategia de comunicación publicitaria. Recuperado el 25 de abril de 2019, de https://www.utel.edu.mx/blog/10-consejos-para/estrategia-de-comunicacioncampanas-publicitarias/

Soria, M. D. (2015). Plan de medios de comunicación e internet (UF2398). Madrid: CEP S.L. Recuperado el 7 de septiembre de 2019, de https://ebookcentral.proquest.com/lib/uleamecsp/reader. action?docID $=4499070 \&$ query $=$ plan $\% 2 B d e \% 2 B$ medios \#

Vasconez, T. (22 de Enero de 2016). Vallas Publicitarias. Recuperado el 27 de enero de 2019, de Wordpress. com: https://mktadstrategies.wordpress.com/2016/01/22/vallas-publicitarias/ 